\title{
The Frontal Sinus and Frontal Recess: Anatomical, Radiological and Surgical Concepts
}

\author{
Camila S. Dassi ${ }^{1,2(-)}$ Flávia R. Demarco ${ }^{1,2}$ João Mangussi-Gomes ${ }^{1,2}$ Raimar Weber ${ }^{2}$ () \\ Leonardo Balsalobre ${ }^{1,2}$ Aldo C. Stamm ${ }^{1,2}$ \\ 1 São Paulo Skull Base Center, São Paulo, SP, Brazil \\ 2 São Paulo Ear, Nose, and Throat Center, Hospital Edmundo \\ Vasconcelos, São Paulo, SP, Brazil \\ Address for correspondence Aldo C. Stamm, MD, PhD, Rua Afonso \\ Braz, 525, Cj 13, São Paulo 04511-011, Brazil \\ (e-mail: astamm@terra.com.br).
}

Int Arch Otorhinolaryngol 2020;24(3):e364-e375.

\author{
Abstract \\ Keywords \\ - frontal sinus \\ - frontal recess \\ - frontal sinus drainage \\ pathway \\ - endoscopic sinus \\ surgery \\ - draf classification \\ - modified lothrop \\ procedure
}

Introduction The frontal sinus (FS) is the most complex of the paranasal sinuses due to its location, anatomical variations and multiple clinical presentations. The surgical management of the FS and of the frontal recess (FR) is technically challenging, and a complete understanding of its anatomy, radiology, main diseases and surgical techniques is crucial to achieve therapeutic success.

Objectives To review the FS and FR anatomy, radiology, and surgical techniques. Data Synthesis The FS features a variety of anatomical, volumetric and dimensional characteristics. From the endoscopic point of view, the FR is the point of greatest narrowing and, to have access to this region, one must know the anatomical limits and the ethmoid cells that are located around the FR and very often block the sinus drainage. Benign diseases such as chronic rhinosinusitis (CRS), mucocele and osteomas are the main pathologies found in the FS; however, there is a wide variety of malignant tumors that can also affect this region and represent a major technical challenge to the surgeon. With the advances in the endoscopic technique, the vast majority of diseases that affect the FS can be treated according to Wolfgang Draf, who systemized the approaches into four types (I, Ila, IIb, III).

Conclusion Both benign and malignant diseases that affect the FS and FR can be successfully managed if one has a thorough understanding of the FS and FR anatomy, an individualized approach of the best surgical technique in each case, and the appropriate tools to operate in this region.

\section{Introduction}

Surgical management of the frontal sinus (FS) is considered the most difficult and challenging part of endoscopic sinus surgery. The idiosyncrasies of the frontal sinus drainage pathway (FSDP) anatomy and its intimate proximity to the orbit and skull base may lead the surgeon to its inadequate dissection and consequently expose the patient to major complications. Meticulous anatomical knowledge of this region and proper surgical planning that starts before the patient enters the operating room is mandatory for any otolaryngologist to perform a safe and successful surgery. This paper will provide a comprehensive overview of the most useful concepts and techniques regarding frontal sinus surgery.

\section{Anatomical and Radiological Considerations}

Similarly, as with any surgery, a thorough anatomical knowledge is the key part of a successful surgical procedure. Due to the proximity of the FS to the orbit and skull base, special care must be taken during endoscopic sinus surgery of the FS. ${ }^{1}$ The received

April 24, 2020

accepted

May 10, 2020
DOI https://doi.org/

10.1055/s-0040-1713923. ISSN 1809-9777.
Copyright $\odot 2020$ by Thieme Revinter

Publicações Ltda, Rio de Janeiro, Brazil
License terms

()ㅇ (1) $\Theta \circledast$ 
FS is an air space located in the anterior cranial vault and is surrounded by two walls of cortical bone. Previous studies referred to the FS as a "large ethmoid air cell" given the common embryological and anatomical relationships between the FS and the ethmoid sinus. ${ }^{2,3}$

The two theories of embryological origin are that the FS develops as a result of direct expansion of the infundibulum and frontonasal recess, or as an ascending epithelial migration of the anterior ethmoid cells that infiltrate the frontal bone between its 2 walls during the $16^{\text {th }}$ week. The FS begins as an insignificant pneumatization in the newborn and becomes radiographically visible around the age of 4 years old. Craniofacial growth is synchronous with the FS and its peak expansion occurs at $\sim 18$ years old. ${ }^{4}$

The FS has great anatomical, volumetric and dimensional variability and can reach enormous proportions, with projections into the zygomatic, supraorbital recesses and parietal bones. Unilateral or bilateral FS aplasia is seen in between 3 and $5 \%$ of individuals. ${ }^{4}$ Anatomical understanding of the frontal sinus drainage pathway (FSDP) complex, specially the frontal recess (FR), is twofold for a favorable surgical outcome.
Resembling an hourglass shape, the FSDP is formed by the frontal ostium superiorly and the FR inferiorly. ${ }^{2,5}$ Described as a connection between the FS and the anterior ethmoid cells, the FR is an inverted, cone-shaped space with the superior narrow end at the internal frontal ostium. The lower limit is wider than the superior one and blends into the anterior ethmoid cells. ${ }^{6}$ The agger nasi cell (ANC) and frontal beak forms the anterior limit of the FR, while the posterior limit consists of the ethmoid bulla and skull base. The medial wall of the orbit and lacrimal bone lies lateral to the FR, and the vertical portion of the middle turbinate forms its medial limit. ${ }^{7,8}$ Anatomical variations of the inferior third of the FSDP are the main source of obstruction and resulting FS disease (- Fig. 1).

The ANC is the most anterior ethmoid cell, marking the anterior limits of the FR, and is therefore used as a reference point for accessing the FS. The extent of pneumatization of the ANC rather than the number or site of cells better determines the endoscopic accessibility to the FS. ${ }^{9}$ The union of its medial wall with the uncinate process (UP) forms the "vertical bar", which is a useful landmark to achieve a correct identification of the FR and FS (-Fig. 2). ${ }^{10}$ Usually, the ANC

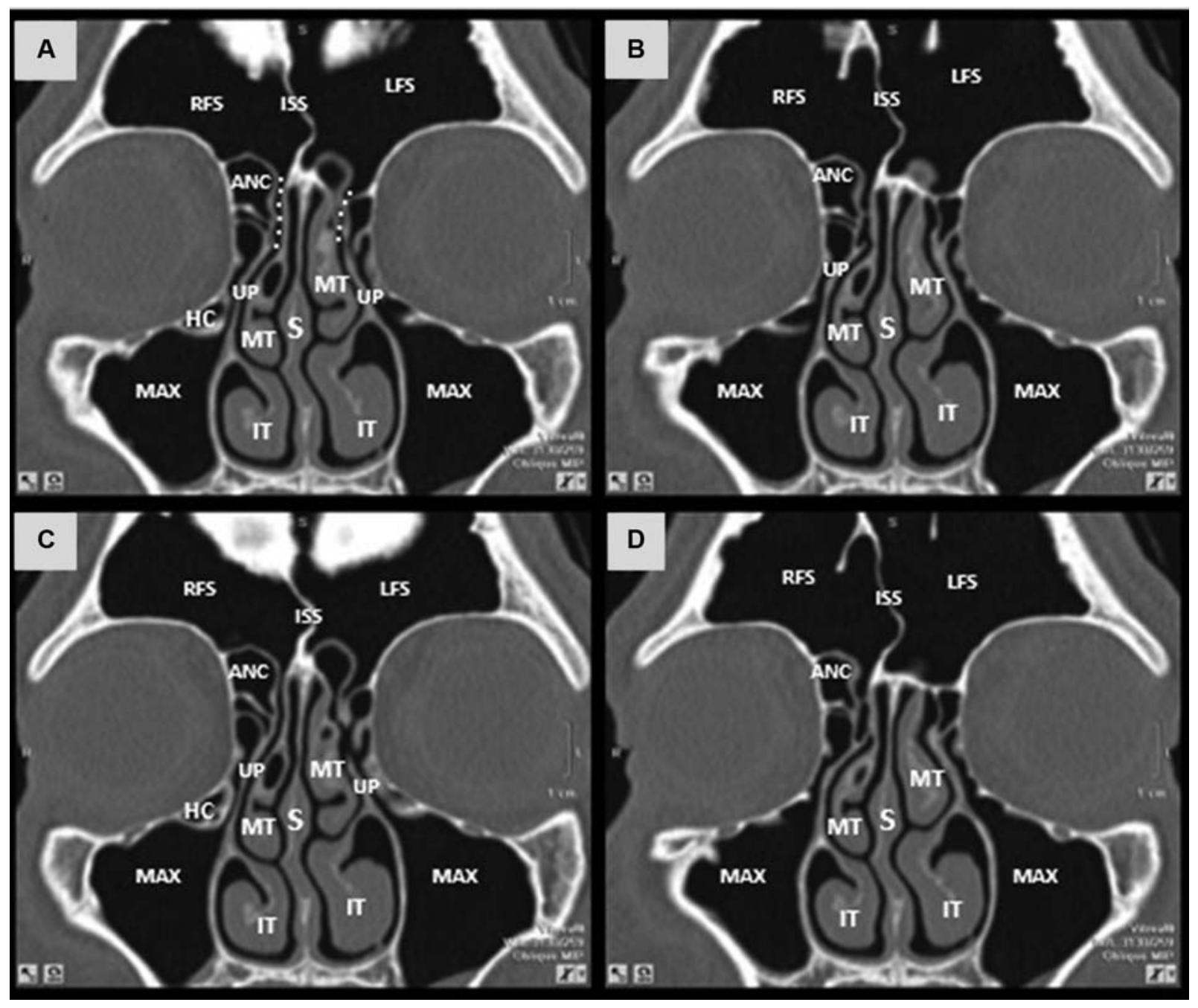

Fig. 1 Coronal sections (A-D) computed tomography scan depicting the anatomy of the frontal sinus drainage pathway and surrounding structures. ANC = agger nasi cell; RFS = right frontal sinus; white dotted line = frontal sinus drainage pathway; ISS = intersinus septum; IT = inferior turbinate; $\mathrm{LFS}=$ left frontal sinus; $\mathrm{Max}=$ maxillary sinus; $\mathrm{MT}=$ middle turbinate; $\mathrm{S}=$ nasal septum; $\mathrm{HC}=$ haller cell; $\mathrm{UP}=$ uncinate process. 


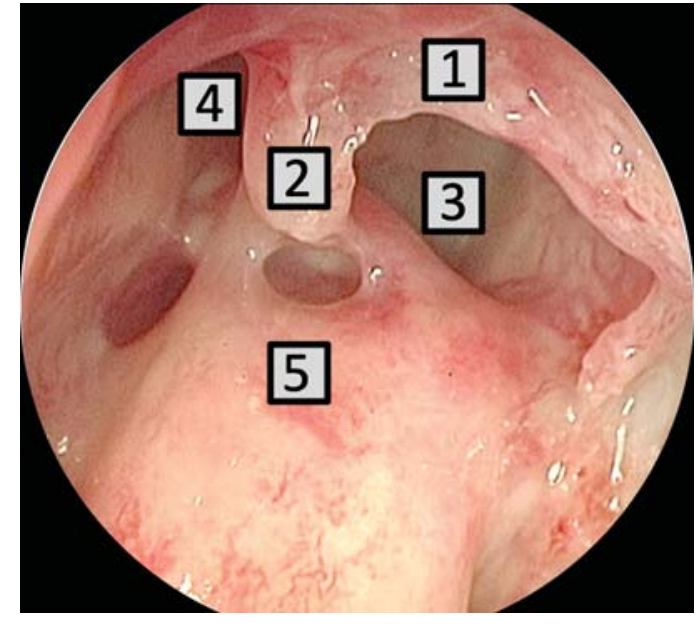

Fig. 2 Endoscopic anatomy of the left frontal recess. Uncinate process (1), vertical bar (2), agger nasi (3), frontal sinus drainage pathway (4) and ethmoidal bulla (5).

has no direct contact with the ethmoid bulla or the middle turbinate, so the FSDP lies posterior and medial to the ANC. When the ANC is broadly pneumatized in the mediolateral direction, it displaces the vertical bar medially, so that this structure is next to the vertical lamella of the middle turbinate - with this anatomical variation, the FSDP is narrowed and positioned posterior to the ANC. The ANC can also be minimally pneumatized, so there is still space left between the "vertical bar" and the middle turbinate. In this case, the FSDP lies medial to the ANC. ${ }^{11}$

The position of the superior attachment of the UP and extensive pneumatization of surrounding ethmoid cells defines the shape and width of the FR. Different insertions of the superior portion of the UP are also used as a landmark for the FSDP location, as described by Stammberger. ${ }^{12}$ If this insertion occurs directly on the lateral wall, the FR will drain into the middle meatus, while in the remaining cases, in which the UP is inserted at the base of the skull or middle turbinate, the FS and FR drain into the ethmoidal infundibulum. Nowadays, this classification is merely dogmatic as multiplanar reconstruction computed tomography (CT) has shown that the UP can have multiple simultaneous superior attachments (orbit, skull base and middle turbinate). ${ }^{7,10,13}$

Regarding the posterior boundary of the FR, the anterior wall of the ethmoid bulla forms a complete lamella by projecting its superior attachment onto the skull base. This forms a cap that covers the anterior ethmoid artery, with the FR usually lying between 2 and $4 \mathrm{~mm}$ from the artery (-Fig. 3). Since the ethmoid bulla forms the posterior limit of the FR, its preservation during FR dissection provides an essential landmark for the posterior limit of dissection, preventing injury to the skull base and anterior ethmoid artery. ${ }^{5,14}$

The FR has variable dimensions - both in the anteroposterior and mediolateral diameters, which can be narrowed by adjacent cells. Posterior to the FR, the supraorbital ethmoid cells pneumatize superiorly from the level of the ethmoid to above the orbit, extending behind the FR. Suprabullar cells appear above the ethmoid bulla and pneumatize to the skull

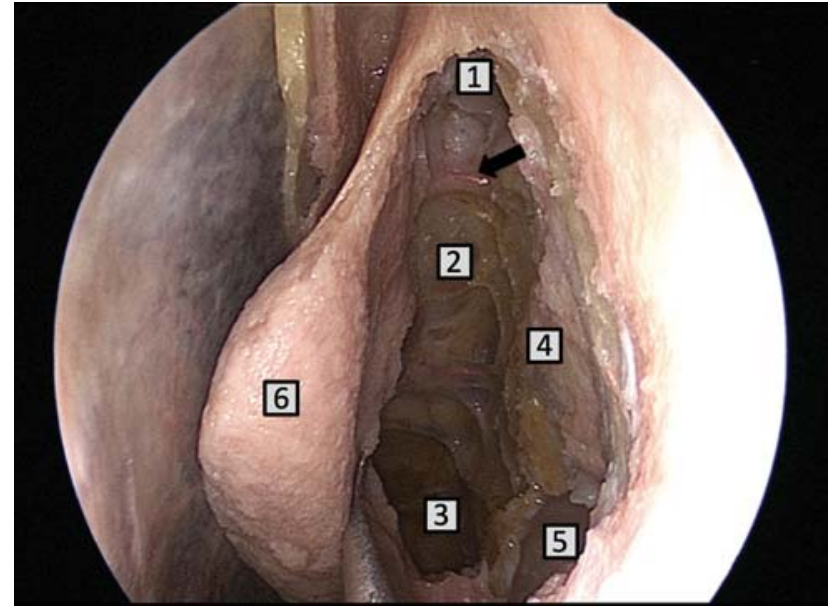

Fig. 3 Endoscopic anatomy of the left anterior ethmoid artery and its relations. Anterior ethmoid artery (arrow), left frontal sinus (1), skull base (2), left sphenoid sinus (3), left lamina papyracea (4), left maxillary sinus (5), left middle turbinate (6).

base, but do not enter the FS, whereas frontal bullar cells pneumatize superiorly traversing the frontal beak into the FS. In some cases, the intersinus septum cell will also be pneumatized, narrowing and laterally displacing the FR. ${ }^{6}$

There are also cells located on the anterior wall of the FR, above the ANC. There are several classifications for these cell types. Traditionally, the most widely used is the Bent and Kuhn classification, with 4 main cell types. Type 1 is defined when there is only 1 cell above the ANC; type 2 occurs when there are $\geq 2$ cells above the ANC; type 3 occurs when a large cell pneumatizes into the FS (- Fig. 4); and type 4 when there is an isolated cell inside the FS. ${ }^{15}$ However, it is unlikely that any frontal cell has no communication with the ethmoid sinus or nasal cavity, given the embryologic development of the FS. Therefore, we do not agree with the classification of a type 4 cell as an isolated cell.

Recently, Wormald et al described an anatomical classification (international frontal sinus anatomy classification [IFAC]) based on three cell types: the anterior cells (ANC, supra agger cell, supra agger frontal cell) that push the FSDP medial, posterior or posteromedially; the posterior cells (supra bulla cell, supra bulla frontal cell, supraorbital ethmoid cell) that push the drainage pathway anteriorly; and medial cells (frontal septal cell) that push the drainage pathway laterally. ${ }^{16}$

Computed tomography is mandatory for the understanding of the anatomy of the patient and individualized surgical planning. It is recommended to evaluate the anteroposterior diameter in the sagittal plane, while the mediolateral diameter is best evaluated in the coronal plane. These measurements usually clarify the degree of difficulty in dissecting the FR. The wider the diameter between the frontal beak and the posterior edge formed by the skull base, the easier the surgical dissection. In cases of narrow diameters, special care must be taken so that the mucosa of the FR is not stripped, as iatrogenic scarring may occur in the postoperative period. Magnetic resonance imaging (MRI) is recommended, especially in cases of intracranial or progressive orbital complications of rhinosinusitis or benign or malignant tumors. ${ }^{17,18}$ 


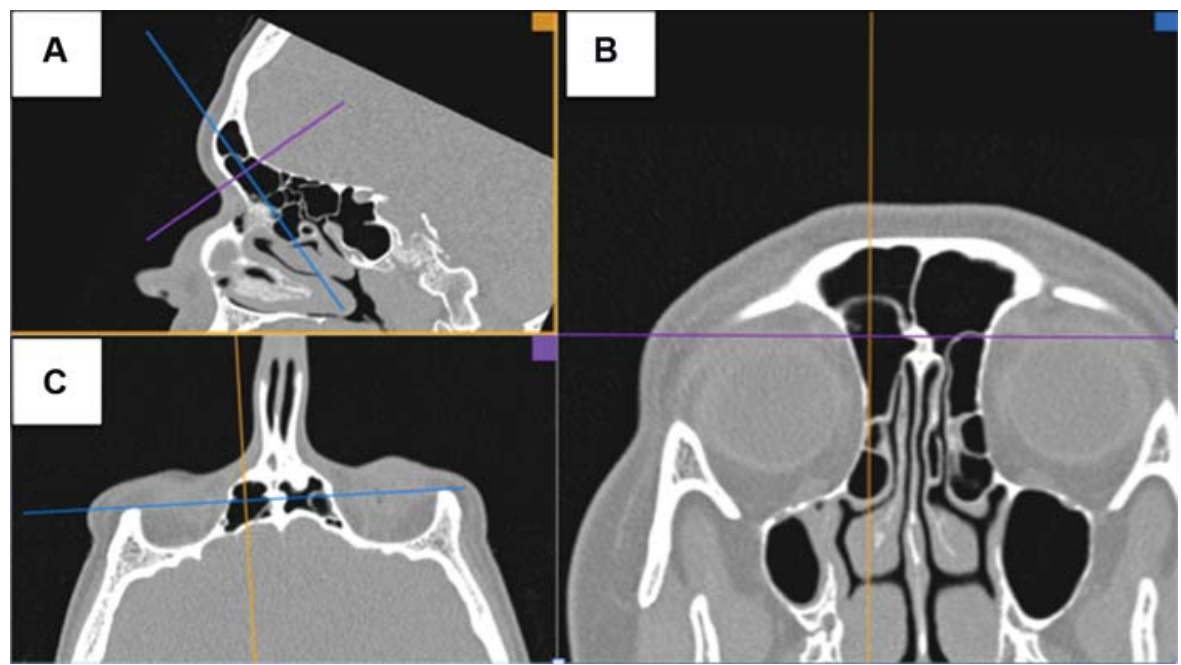

Fig. 4 Multiplanar reconstruction of computed tomography (CT) scan using OsiriX DICOM viewer. (A) parasagittal CT section, (B) oblique section for true coronal plane, (C) oblique section for true axial plane. Kuhn type 3 cell/IFAC supra agger frontal cell. MPR $=$ multiplanar reconstruction, $\mathrm{CT}=$ computed tomography, IFAC = international frontal sinus anatomy classification.

In summary, to operate in the FR, a clear three-dimensional configuration of the FSDP complex, of the UP and of the cells surrounding the FR is mandatory. More crucial than naming the cells related to the FS and FR is a thorough evaluation of these cells on a multiplanar reconstruction (MPR) of the CT scan. ${ }^{19}$ There are several types of imaging software that are helpful in this task. Anatomical uncertainty while dissecting the FR may result in surgical failure due to inadequate technique, as well as increased risk of iatrogenic injury to critical structures such as the orbit, skull base and the anterior ethmoid artery. ${ }^{20,21}$

\section{Clinical and Surgical Considerations}

The disease process and FS and FR anatomy should direct the FS surgery. As for all other sinuses, the surgical goal is to identify the FSDP and expand its recess (FR). Simply aerating the FS can treat some diseases caused by obstructive problems. Tumors, on the other hand, usually require broader resection of the frontal sinus mucosa and its bony limits. ${ }^{17}$

Widely accepted surgical approaches to chronic rhinosinusitis (CRS) highlight that proinflammatory cells and tissues, such as mucus, polyps and altered bone should be removed as much as possible to obtain a better therapeutic result. Furthermore, the surgical goal in patients with advanced CRS, especially if there is irreversible mucosal disease, is to create large drainage openings to allow optimal topical anti-inflammatory therapy administration. However, the "stripping" of the mucosa should generally be avoided to prevent additional fibrosis and neo-osteogenesis. ${ }^{22,23}$

\section{Preoperative Considerations}

\section{Imaging}

A thorough preoperative radiological analysis of the anatomy of the FS and its drainage pathway aids the success of the operative procedure. ${ }^{17}$ A recent CT scan, and MRI if needed, must be present in the operative theater. Key anatomical features on the CT scan should be highlighted during the surgical planning and reviewed in the theater just prior to the surgical procedure:

- Nasal cavity: width, obstruction, septal deviation.

- Inferior turbinates: size, position, bony and mucosal thickness, presence (if revision surgery).

- Middle turbinates: anatomical variations, attachment, presence and lateralization (if revision surgery).

- Uncinate process: attachments, proximity to the orbit, remaining fragments (if revision surgery).

- Maxillary sinus: Haller cells, accessory ostia, pneumatization, infraorbital nerve, dental roots, relation to the orbit.

- Frontal sinus/frontal recess/anterior ethmoid: pneumatization, FSDP position and adjacent cells (as above), anteroposterior and mediolateral diameter of the FS, thickness of the frontal beak, anterior ethmoidal artery, lamina papyracea.

- Posterior ethmoid/Sphenoid sinus: width and pneumatization, Onodi cells, optic nerve, internal carotid artery, $\mathrm{N}$. V2, vidian nerve, septations, bone dehiscence.

- Skull base: Height, course, attention to the depth of fovea ethmoidalis (Keros) and its symmetry.

- Brain, orbit and nasopharynx: particularities.

- Paranasal sinus: extent of disease, bone alterations.

\section{Equipment}

Due to technological advancements, the endoscope combines a wide-angle view to a detailed high definition image, even in bloody sites. ${ }^{17}$ Most conditions affecting the FS can be accessed using the endonasal approach, via the use of angled optics $\left(30^{\circ}, 45^{\circ}\right.$ and $\left.70^{\circ}\right)$ and by angled instruments specific for the FS, such as the "giraffe" sinus forceps, the Hosemann forceps for the FS (frontal punch) and the angled Kerrison rongeur. Frontal sets usually consist of angled instruments $\left(55^{\circ}\right.$ and $\left.90^{\circ}\right)$ : angled curettes, frontal ostium seekers, frontal sinus giraffe forceps, and FS through-cutting punches. It is important to double-check the availability and 
sterilization of appropriated frontal instrumentals prior to anesthetic induction. ${ }^{24}$

Powered instrumentation, that is, shaver or microdebrider, is a cylindrical suction-cutting device that removes tissue continuously by oscillating or rotating knives in an interior cannula. Different diameters, angle of deflection and positioning of the opening enable more careful and precise tissue resection. ${ }^{25}$ Continuous suction of blood and secretions allows targeted resection of tissue while maintaining a clear surgical field. It can also facilitate rapid and continuous removal of polyps and exophytic tumor masses. The $4 \mathrm{~mm}, 360^{\circ}$ rotatable, $12^{\circ}, 40^{\circ}$ and $60^{\circ}$ angled debrider blades are most frequently utilized by our group during endoscopic FS surgery. It is usually used in short on/off bursts to avoid mucosal stripping and prevent iatrogenic scarring. Nevertheless, attentive visualization of the tip opening is mandatory to avoid major artery injury and orbital and intracranial complications. ${ }^{26}$

For effective bony resection, in the context of an extended FS surgery, curved burrs are required. In our practice, highspeed coarse-diamond $4 \mathrm{~mm}, 15^{\circ}$ and $40^{\circ}$ angled burrs are used for a more aggressive drilling in addition to a $40^{\circ}$ or $60^{\circ}$ diamond burr for drilling more critical sites. ${ }^{17}$

Navigation systems have the potential to improve the anatomical orientation of the surgeon and are meant to reduce the complication rate. However, the implementation of an image-guided system increases the costs of the surgery. Therefore, this technology is reserved for selected cases such as revision FS surgery, in which the anatomical landmarks are severely displaced by previous procedures or due to the severity of the disease. If a navigation system is implemented, it should be appropriately prepared prior to the beginning of the surgical procedure with specific CT scans downloaded to the system. The current precision of the image-guided system must always be critically questioned. It is important to verify the preciseness of the system at the beginning of each intervention and also throughout the course of the surgical procedure. Of note, this technology is meant to be used only as an adjunct to the thorough anatomical knowledge and surgical expertise of the surgeon (-Fig. 5). ${ }^{17,27,28}$

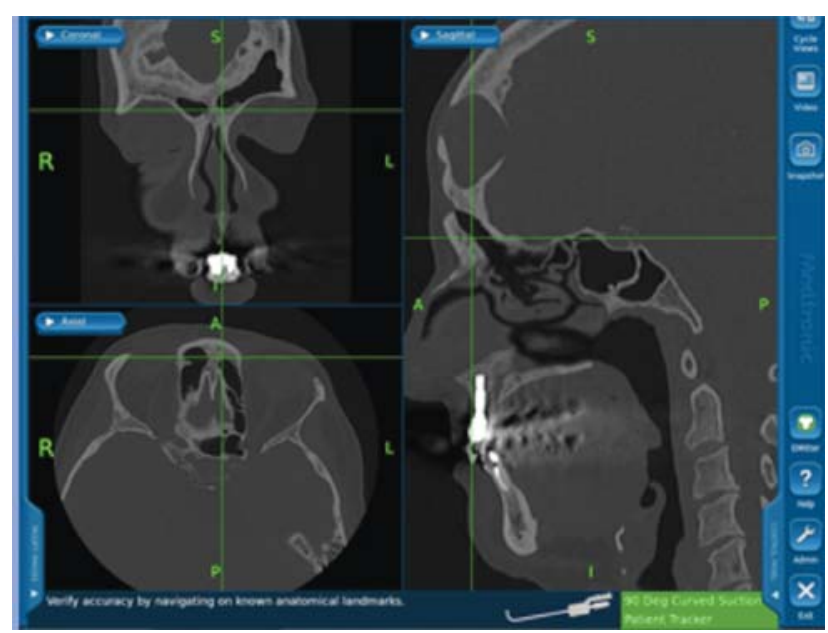

Fig. 5 Image-guided system screen shot of a patient with a frontal mucocele that underwent a Draf III procedure.
The drugs to be applied should be labeled correctly to avoid local infiltration of a high concentrated adrenaline solution, such as the adrenaline/saline 1:2,000 that can result in cardiac arrest. A bipolar and suction monopolar coagulation system should be installed and its functionality should be tested prior to the beginning of the first incision.

To improve the image quality by avoiding lens soiling and fogging, commercial anti-fogging solutions are available. An alternative option, which is broadly used by our team, is a simple solution made with $10 \mathrm{ml}$ of $2 \%$ chlorhexidine gluconate and $5 \mathrm{ml}$ of $0.9 \%$ saline solution that is mixed up and poured on the top of 3 pre-counted small swabs and placed into a small round bowl. The bowl is set up on the side of the head of the patient to be handy if needed.

\section{Operative Considerations}

\section{Anesthesia}

Hypotensive total intravenous anesthesia (TIVA) using propofol and remifentanil is preferred in endoscopic sinus surgery due to the reduction of blood loss and surgical time in comparison to inhaled anesthesia. ${ }^{29}$ It is important the maintenance of a low heart rate ( $<60$ beats/minute) and mean blood pressure at $\sim 75 \mathrm{~mm} \mathrm{Hg}^{30}$

\section{Positioning}

The patient is usually positioned in a $15^{\circ}$ reverse Trendelenburg position (RTP) with the head slightly extended and turned toward the surgeon. It improves surgical field of view and reduces intraoperative bleeding in comparison with the horizontal position (HP). ${ }^{31}$

\section{Tranexemic Acid}

The application of tranexamic acid, systemic or topical, aims to decrease intraoperative blood loss and improve the quality of the surgical field. ${ }^{32}$ In our practice, we routinely administrate $1 \mathrm{~g}$ of intravenous tranexemic acid during the anesthetic induction if there is no contraindication for its usage.

\section{Prophylactic Antibiotics}

Surgical antibiotic prophylaxis consists in the administration of an antibiotic prior to the contamination of a sterile site. It should be initiated during the induction of anesthesia, 30 minutes prior to the incision. We routinely use antibiotic prophylaxis in patients with CRS, cerebrospinal fluid (CSF) leaks and in skull base surgeries. Other patients must be individualized. Cefazolin is our choice of antibiotic due to its properties of intravenous administration, effectiveness against agents that might colonize the nasal cavity in association with minimal side effects and cost-effectiveness. The dose for a regular adult patient is $2 \mathrm{~g}$ and it should be repeated during surgery (1g) every 3 hours. $^{33}$

\section{Preparation of the Surgical Site}

Antiseptic agents such as povidone-iodine and $4.0 \%$ aqueous solution of chlorhexidine are the most commonly used solutions for facial skin preparation. 


\section{Topical Vasoconstriction}

The nasal cavity is prepared with cotton neuropatties soaked with adrenaline $(1: 2,000)$ to provide a dry field. Infiltration of the nasal septum mucosa with $7.5 \%$ ropivacaine $1: 100,000$ is performed when a septoplasty is needed.

\section{Surgical Technique}

The extent of surgery is individualized according to the disease process and patient symptomatology. It is also based on the individual anatomy and on patient-specific factors and comorbidities. ${ }^{17}$ A septoplasty should be performed in cases of symptomatic nasal obstruction, or for improving surgical access to the middle meatus. A full view of the axillary region of the middle turbinate is needed for endoscopic sinus surgery. ${ }^{34}$

According to Draf, the endoscopic approaches to the FS are systematized into four types (Draf I, IIa, IIb and III or modified Lothrop) with successive increase in its operative complexity. Consequently, the surgeon is able to adapt the extent of the FS surgery to the severity of the underlying condition (-Fig. 6). ${ }^{35}$

\section{Draf I}

A Draf I procedure is defined by an ethmoidectomy that aims to better aerate the region of the FR. It includes the resection of the UP in addition to the resection of parts of the medial lamella of the ANC and the anterior wall of the ethmoid bulla, if needed. Further manipulation in the region of the FR recess should be avoided to prevent scarring. ${ }^{17,35}$

This approach is indicated when there is only minor disease in the FS. In these cases, the FS is treated as a result of improved drainage via the ethmoid cavity. Draf I procedures can also be performed for acute complicated frontal sinusitis that failed medical management. Diseases that are associated with poor quality of mucosa such as aspirin triad, both asthma and polyposis, or intersinus septal cells are more likely to fail this procedure. ${ }^{17,35}$

The early steps of the procedure are performed with a $0^{\circ}$ endoscope. The middle turbinate is gently displaced medially with a freer elevator. The UP is identified and then medialized with the hooked end of an ostium seeker. An uncinectomy may be performed in anterior-posterior direction or retrograde from posterior to anterior. In the first case, either the sharp end of a freer elevator or a sickle knife can be used to incise the UP near to its attachment at the lateral wall. The incision is extended in a superior and inferior direction and two cuts are made (superior and inferior) using sharp endoscopic scissors. In the retrograde technique, a backbiting forceps is used to resect the point of intersection between the horizontal and vertical portions of the UP. Its fragments are resected either with a straight blakesley forceps or a microdebrider $\left(0^{\circ}\right.$ or $\left.12^{\circ}\right)$. After removal of the mobilized part of the UP, the remaining horizontal part can be dissected with the smaller end of the ostium seeker. A submucosal resection of the horizontal portion of the UP is performed and the trimming of the surplus mucosa follows it. Thus, the natural maxillary ostium is completely exposed. ${ }^{35}$

Additional thorough anterior ethmoidectomy can be performed with resection of anterior ethmoid cells that are surrounding the frontal recess, with no further manipulation of frontoethmoidal cells. ${ }^{6}$

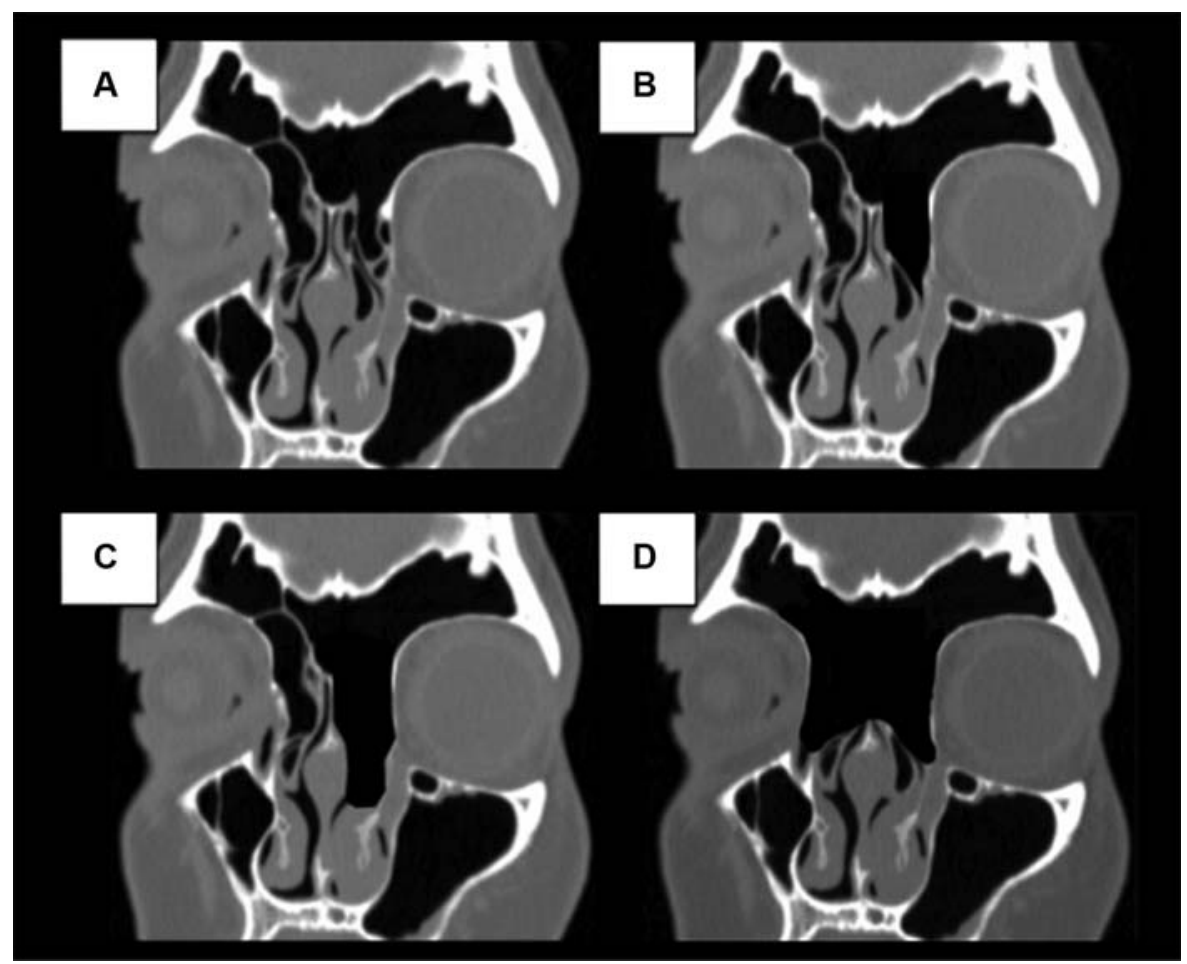

Fig. 6 Computed tomography (CT) scans (coronal section) illustrating the endoscopic approaches to the frontal sinus according to Draf. (A) preoperative CT scan, (B) Draf Ila, (C) Draf IIb and (D) Draf III. CT= computed tomography. 


\section{Draf IIa}

The Draf Ila includes the resection of all aforementioned ethmoid cells that impair the FS drainage. It is achieved after a complete ethmoidectomy, including the resection of all cells related to the FS and FR, between the lamina papyracea and the middle turbinate. Draf Ila frontal sinusotomy is indicated for a variety of pathologies such as refractory chronic frontal sinusitis, CRS with polyposis, barosinusitis, complicated acute frontal sinusitis that failed Draf I, mucocele and benign tumors. ${ }^{36}$

For anatomic location, the ANC, specifically its medial lamella ("vertical bar"), along with the ethmoid bulla are very important landmarks for the FSDP ( - Video 1 ). ${ }^{10}$ This procedure demands technical expertise so it is recommended that experienced otolaryngologists should perform it.

\section{Video 1}

Draf II cadaveric dissection. Online content including video sequences viewable at:

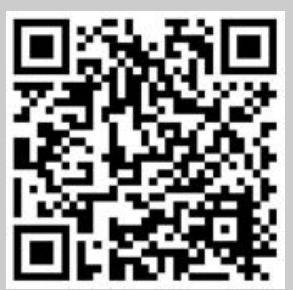

https://www.thieme-connect.de/products/ejournals/ html/10-1055-s-0040-1713923-iao-20-0113-v1.mp4.

In all possible cases, our endoscopic team prioritizes an "intact bulla" technique for Draf Ila procedure. According to Rudert, the ethmoid bulla, or at least its anterior wall, should be preserved as long as possible. ${ }^{37,38}$ Initially using a $0^{\circ}$ endoscope, an uncinectomy is performed as described earlier in the present article. In most cases, after the resection of the superior portion of the visible UP, the terminal recess will be visualized and care must be taken to not mistakenly identify it as an ANC.

An angled endoscope $\left(30^{\circ}\right.$ or $\left.45^{\circ}\right)$ and a curved microdebrider blade are then used to remove the anterior wall of the terminal recess. The limit of dissection is the hard lacrimal bone superiorly, just lateral to the junction of the anterior wall of the terminal recess with the middle turbinate and medial to the lamina papyracea. Subsequently, the anterior wall of the ANC is partially removed with an angled forceps or microdebrider, preserving its medial wall. A FS seeker is then used to identify the FS; its opening is usually located posteromedial to the "vertical bar." Next, the medial wall of the ANC is pushed laterally and its fragments are removed. The posterior limit of resection is delineated by the intact bulla. This type of dissection protects the ethmoidal dome and the anterior ethmoid artery. The endoscope is switched back to a $0^{\circ}$ and the anterior wall of the ethmoid bulla is resected. Several instruments such as through-cutting punches, Kerrison punches, angled curettes and microdebrider can be used. The remaining frontoethmoidal cells can be fractured in a forward and downward direction. This process is repeated until the internal frontal ostium is completely visualized with no bone fragments covering it. It is essential to avoid inadvertent mucosal removal from the FR to prevent FS stenosis. ${ }^{6}$ Any further sinus or nasal cavity surgery is then performed according to the extension or the characteristics of the disease.

\section{Draf IIb}

A Draf IIb involves the resection of the floor of the FS, extending beyond the natural drainage of the FS, as it involves the space between the lamina papyracea and the nasal septum. Resection of the axilla and the most anterosuperior portion of the middle turbinate are completed. The posterior limit of the resection will be the skull base. The frontal beak is drilled out, delineating the anterior boundary of the sinusotomy. 6,35

The indications for a unilateral procedure usually are clinical and radiological evidence of chronic frontal disease such as CRS, mucocele and benign tumors that are limited to one side with an asymptomatic aerated contralateral sinus. $^{17}$

In our experience, the Draf IIb procedure is not frequently indicated for inflammatory disease. In most cases, the neoosteogenesis process that starts along with the drilling of the FS floor is more harmful than the inflammatory process itself. Usually, if there is an indication of resecting the FS floor for CRS, a Draf III is performed instead of a Draf IIb.

\section{Draf III}

The Draf III procedure consists of the union of the two FSs through the resection of all anterior ethmoid cells, anterior part of the middle turbinates, FS floor bilaterally, adjacent parts of the nasal septum and intersinus septum. The main indications for a Draf III are poorly controlled massive nasal polyposis, severe frontal recess osteitis, and failure of less aggressive procedures on maintaining a patent frontal sinus; management of frontal sinus CSF leaks, encephaloceles, and trauma; frontal mucoceles and salvage of obliterated frontal sinus. This is also one of the steps of a transcribriform approach during the access to the anterior skull base (-Fig. 7). For most inflammatory pathologies of the FS, Draf III is usually employed if well-performed Draf II procedures and directed medical therapy have not succeeded in establishing adequate control of the disease. However, it can be considered as a primary procedure particularly in patients with mucoviscidosis, Kartagener syndrome and ciliary immotility syndrome. ${ }^{35}$

This can be done through an "inside-out" technique that consists of the identification of the frontal recesses, followed by their enlargement before progressing medially to communicate the bilateral openings into a single neoaperture. As an alternative, the "outside-in" technique involves drilling away most of the frontal beak before the identification of the FRs. ${ }^{39}$ The "inside-out" approach is how we approach most of 

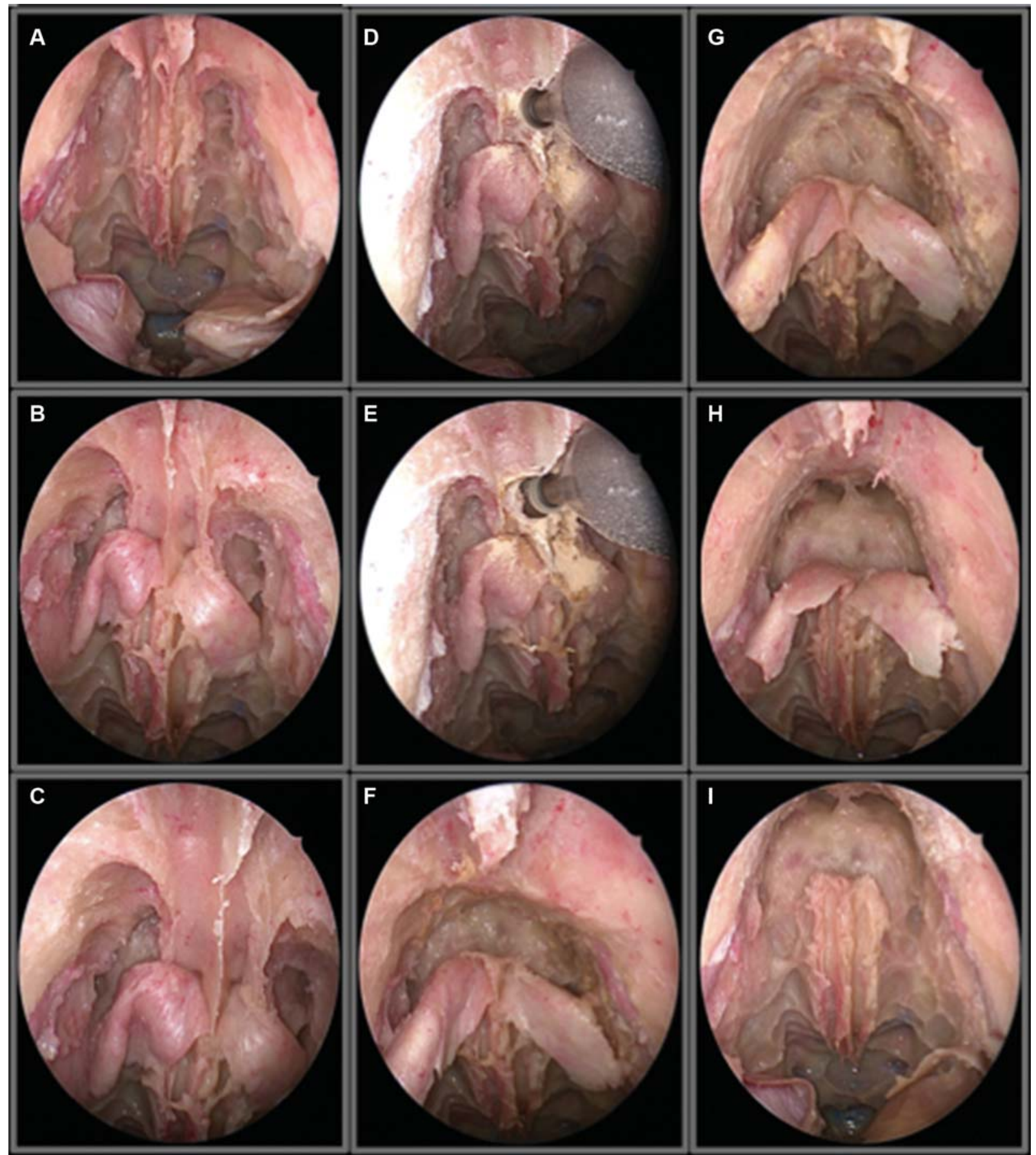

Fig. 7 Endoscopic view of a Draf III as a step for a transcribriform approach. (A) view of the cribriform plate and frontal recess. (B) bilateral identification of the first olfactory fiber, (C) view after partial drilling of the frontal sinus floor, (D) drilling of the bony junction between the two frontal sinus, (E) visualization of the left frontal sinus, (F) view after communicating both frontal sinuses, (G) further drilling of the anterior table of the frontal sinus, (H) and (I) final aspect after a complete drill out of the frontal sinuses.

our Draf III procedures. However, in cases of extremely narrow FRs in association with dense osteitis of the FR, an outside-in approach is preferred.

The limits of maximal resection are the external periosteum of the frontal process and the anterior glabela. The lateral limits are the medial wall of the orbits and the posterior limits are the first olfactory fibers on both sides. ${ }^{39}$

The procedure starts with a bilateral frontal sinusotomy (Draf Ila) as described above. Next, a 1.5-2 cm septal window is performed in the caudal area of the FS floor and extends dorsally to the attachment of the septum on the FS floor. It will allow access to the axilla of the middle turbinates from both sides of the nose. The inferior extension of the septal window ends just below the middle turbinate axilla. Its anterior limit should not extend beyond the nasal bone to maintain dorsal nasal support. The posterior limits of the septectomy are the anterior edges of the partially resected middle turbinates. A colorado-tip (Colorado Needles by 


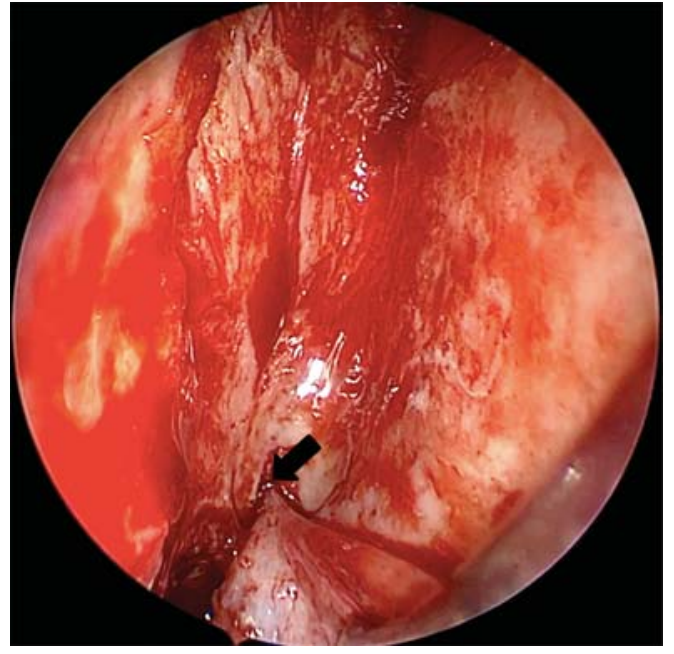

Fig. 8 Draf III first olfactory fiber.

Stryker, Oakland, New Jersey USA) monopolar at a low coagulation setting is useful for demarcating the limits of the septectomy. Although mucosa is often removed, mucosal grafts can be harvested from the septectomy site and can be possibly used to cover the exposed areas at the end of the procedure. $^{35}$

Next, the middle turbinate anterior attachment is trimmed and the mucosa over the axilla of the middle turbinate is resected and the edges are cauterized. The first olfactory fiber is then identified on both sides: the septal angle is identified and the mucosa flap is posteriorly elevated toward the cribriform plate with a suction-freer elevator. The nasal branch of the anterior ethmoid artery will be just anterior to the first olfactory fiber and is commonly mistaken with it (-Fig. 8). ${ }^{40}$

Bone drilling begins on the frontal floor and its limits. With a $45^{\circ}$ endoscope, the use of angled drills is extremely necessary. The endoscope is introduced through one nostril and the drill through the contralateral nostril. This allows more space to work with the instruments. Initially, a $4 \mathrm{~mm}$ $15^{\circ}$ cutting burr or 'coarse-diamond' can be used. Ideally, this drill should have integrated irrigation and suction to speed up the procedure. Drilling starts from inside the FS with an anterior and medial direction, toward the contralateral FS. The FS floor, the frontal beak and the junction of the bony septum with the floor and anterior table of the FS are drilled out aiming to achieve a smooth transition between the anterior frontal table and the nasal bone. More angled burrs, usually $40^{\circ}$, are often required for a better drilling of the anterior portions of the neoaperture. Then, the frontal process of the maxilla should be thinned until the periosteum can be visualized. Care must be taken to not breach it. ${ }^{35,37,39}$

A direct visualization of the first olfactory fiber while drilling the posterior projection along the posterior frontal table is fundamental to not breach the skull base. An angled diamond burr is preferred for this step and allows a more meticulous drilling. The intersinus septum is then drilled out, extending dorsally to the frontal roof (-Video 2). ${ }^{39}$

\section{Video 2}

Draf III cadaveric dissection. Online content including video sequences viewable at:

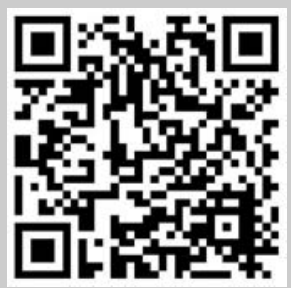

https://www.thieme-connect.de/products/ejournals/ html/10-1055-s-0040-1713923-iao-20-0113-v2.mp4.

Extensive irrigations are performed during drilling to avoid overheating of the surgery site and at the end of the procedure to flush out bone dust and debris. The surgical site is carefully inspected and the hemostasis is reviewed. Mucosal grafts can be placed over bony surfaces and may lead to a wider persisting neoaperture. ${ }^{41}$

At the end of the procedure, a mupirocin-soaked gauze is placed into the frontal sinus in a manner that the packing fulfills the whole sinus. It creates a humid environment that reduces the granulation and scarring process while promotes hemostasis and a "stent" effect by taking space.

A systematic review has shown rates of $>95 \%$ of endoscopy patency of the neoaperture at 28.5 months after a Draf III surgery. ${ }^{42}$ However, some other studies described that there might be a reduction in its diameter for up to 2 years after the procedure. ${ }^{1,43}$ In summary, long-term patency rates vary, but a large neoaperture, with maximization of the Draf III extension, is critical for maintain high patency rates after 2 years of surgery. ${ }^{36,44}$

\section{Complications}

Safe and successful FS surgery requires meticulous planning and profound anatomical knowledge. Reducing intraoperative bleeding is mandatory to improve the visualization of the surgical field and, consequently, enhance the safety of the procedure. ${ }^{45}$

\section{Cerebrospinal Fluid Leak}

Functional endoscopic sinus surgery (FESS) and neurologic surgery are the most common causes of iatrogenic skull-base defects. Certain variations in anatomy, such as an asymmetric or a deep fovea ethmoidalis, increase the risk of a skull base breach. As a general rule, a CSF leak diagnosed intraoperatively should be repaired in the same surgical setting. If a prompt surgical repair of the defect is performed, the success rate of closure is as high as $90 \%$ in the initial surgery and up to $97 \%$ including revision surgery. ${ }^{46}$ A delayed 
detection of the CSF leak exposes the patient to a high risk of meningitis and its complications. ${ }^{17,47}$

A precise anatomical localization of the area of defect is indispensable for a successful reconstruction. In some cases, further surgical dissection may be necessary. Nasal grafts and vascularized septal flaps are generally used to repair the defect. The choice will depend on the size and location of the defect, donor site morbidity, ease of surgical manipulation, and cost. ${ }^{45}$ Multilayered reconstruction with an inlay placement of muscle, fascia or a collagen-based artificial graft might be required for repairing larger defects. Gelfoam (Gelfoam Pharmacia and Upjohn Company LLC. Kalamazoo, Michigan EUA) is usually placed covering the repaired area and the nose is packed. Nasal packing usually remains in place for 2 to 3 days. Lumbar drainage is not routinely indicated.

Postoperatively, some specific measures are recommended. The patient is placed at bed rest for at least 24 hours, $30-45^{\circ}$ positioning of the head of the bed during the first $48-72$ hours and avoidance of activities likely to increase intracranial pressure. ${ }^{17}$

\section{Orbital Complications}

The severity of orbital complications ranges from herniation of periorbital fat, to more serious events such as extraocular muscle disruption and orbital hematoma. An injury to the medial orbital wall and periorbit may produce only minor fat prolapse and, as soon as this is recognized, its precise and locally limited bipolar cauterization can be performed. The remaining surgery can still be finished, but powered instrumentation should be avoided. When using powered instrumentation, the lack of prompt recognition of a periorbital injury may result in severe damage to the tissues that lay beneath the fat, most often the medial rectus muscle but also the optic nerve. ${ }^{26,45}$

During the surgical dissection of the FR, the proximity of the anterior ethmoidal artery to the posterior limit of the FR places this vascular structure at risk for iatrogenic injury and significant bleeding. Initially, when an anterior ethmoidal artery is injured, but not transected, it can be best controlled with meticulous suction of the area and hemostatic packing. Bipolar cautery can be also used if there is persistent bleeding. It is important to avoid surgical manipulation adjacent to an active bleeding area since it can lead to further complications. Unidentified bleeding at the skull base may be indicative of a concomitant CSF leak. ${ }^{45}$

In cases in which the anterior ethmoid artery is roughly pulled, an accidental transection of its intraorbital portion can occur. It can lead to a rapid-onset orbital hematoma and onsequent proptosis of the eye. Examination should include ballottement of the orbit, checking for afferent pupillary defect, and tonometry. ${ }^{48}$ Once suspected, immediate assistance from an ophthalmologist should be required. However, in most cases, there will not be enough time to wait for the ophthalmologist to evaluate the intraocular pressure objectively. In this scenario, the sinus surgeon should perform the decompression of the orbit in a timely manner to avoid permanent visual loss. ${ }^{45}$

A lateral canthotomy with upper and lower lid cantholysis is the most common procedure used to relieve the intra- orbital pressure. The procedure consists of a small incision in the lateral canthus using scissors followed by the transection of the inferior lateral canthal tendon by directing a second cut inferiorly until reaching the orbital rim. Endoscopic orbital decompression with removal of the medial wall of the orbit and subsequent periorbital incisions is also an option for experienced surgeons. ${ }^{49}$

Orbital hematoma with a subacute presentation usually is a result of a slow venous bleeding after a breach of the lamina and periorbita. Its signs and symptoms include orbital swelling, pain, and vision loss that occur over hours, instead of minutes. Removal of any ipsilateral nasal packing is mandatory as soon as an orbital hematoma is suspected. Further, fracture to the lamina papyracea can also cause periorbital ecchymoses. Conservative management and avoidance of nose blowing for 7 days is preconized to prevent subcutaneous emphysema. ${ }^{49}$

\section{Collapsing of the Middle Meatus}

Lateralization of the middle turbinate can potentially lead to undesired obstruction of the FS and it is often associated with synechiae in the middle meatus. Although it is poorly related with worsening of the patient symptoms, it is often mentioned as a reason for failure of FS surgery and necessity of revision surgery. ${ }^{50}$

Some measures and techniques that aim to avoid or reduce the lateralization of the middle turbinate include the preservation of the horizontal part of the basal lamella of the middle turbinate and transseptal sutures. Further, "Bolgerisation" can be used for the creation of an intentional synechiae between the middle turbinate and the nasal septum by targeted injuring these two structures on the same level.

In our experience, the suture of the middle turbinates to the nasal septum with an absorbable suture that keeps its tensile strength for at least 3 weeks is usually performed and has shown good outcomes.

\section{Mucoceles}

Mucoceles are a result of an accumulation of mucus within a confined space. They tend to form when the FSDP is obstructed and usually cause bone erosion and the displacement of surrounding structures, including the orbit and anterior cranial fossa. Orbital symptoms such as proptosis, diplopia and ophthalmoplegia, and cardinal symptoms of CRS are the most common clinical presentation.

In endoscopic FS surgery, mucosal preservation and maintenance of the patency of the FSDP aim to avoid a mucocele formation. ${ }^{7}$ The preferred treatment modality for the vast majority of cases is an endoscopic marsupialization of the lesion. In most cases, at least a Draf Ila procedure is usually required.

\section{Postoperative Care}

The vast majority of FS surgeries are performed on an inpatient basis and overnight stay. Therefore, possible complications occurring during the first hours of the postoperative can be treated immediately. 


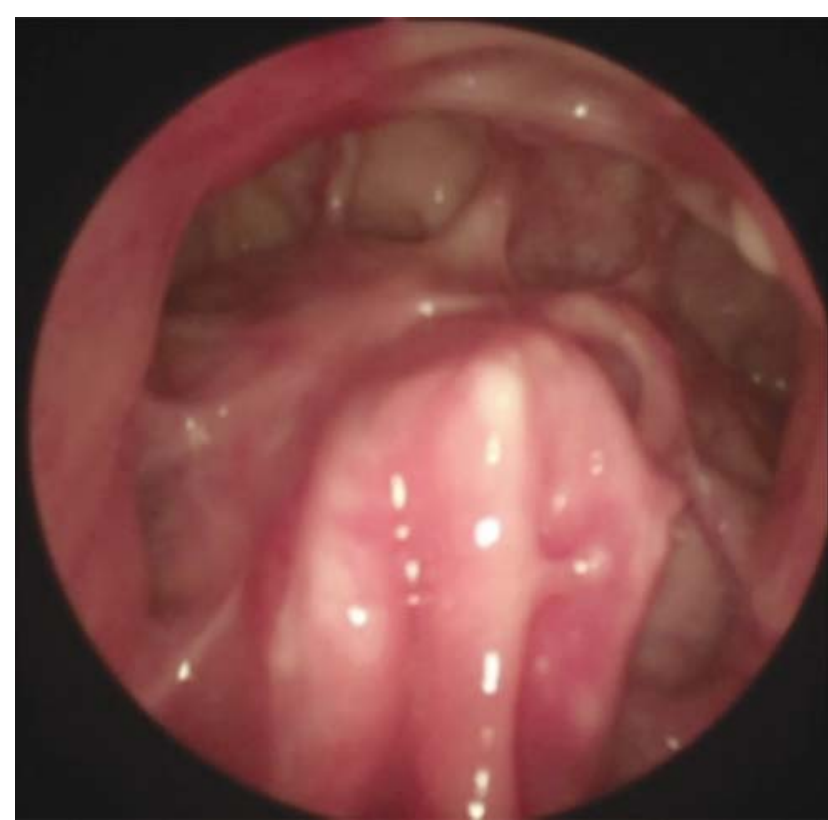

Fig. 9 Six weeks postoperative endoscopic view after a Draf III.

The postoperative care is an integrated part of the surgical procedure and its goal is to promote early mucosal healing and to decrease local inflammation to minimize postoperative symptoms such as pain and infections. ${ }^{17}$

The need for postoperative antibiotics is assessed intraoperatively, but it is not part of the routine. If there is intraoperative evidence of acute inflammation, amoxicillin-clavulanate for 14 days is usually prescribed in association with a 5-day course of prednisone $20 \mathrm{mg}$ daily. Furthermore, nasal rinsing with a disposable 20-cc irrigating syringe with room temperature $0,9 \%$ saline solution is strongly recommended from the first postoperative day on. The patient is oriented to bend over the sink, and with the mouth opened, to irrigate both nostrils with 40 -cc of saline on each side. It is suggested that this irrigation process happens at a minimum of 3 times daily for at least 1 month. In cases of patients with polypoid disease secondary to allergic fungal sinusitis or aspirin-sensitive asthma, oral and topical steroids are strongly advised.

Postoperative debridement is performed with $0^{\circ}, 30^{\circ}$, and $70^{\circ}$ telescopes, straight and curved suctions, and basic FS instruments. Adequate visualization of the internal frontal ostium is crucial after debridement to assure patency. Removal of crusts, clots and fibrin is recommended.

Our routine schedules the postoperative visits for debridements on day 7 , then again on day 14 , and a $3^{\text {rd }}$ visit 6 weeks after the surgical procedure. Nasal packing after Draf III is usually removed during the first visit. With thorough mucosal preservation, patients show near healed FRs on the third visit (-Fig. 9).

\section{Conclusion}

The diseases that affect the FS and FR can be adequately and safely addressed if one has a thorough knowledge of the FS anatomy, an individual indication of the best surgical technique for each case, and if the appropriate instruments are used to operate that site. Even with technological advances in image-guided surgery, FS and FR surgery remains a challenge, and if the surgical principles are not taken into account, damage to noble structures and other complications can occur.

\section{References}

1 Ting JY, Wu A, Metson R. Frontal sinus drillout (modified Lothrop procedure): long-term results in 204 patients. Laryngoscope 2014;124(05):1066-1070

2 Shama SA. Frontal sinus outflow tract: Multi-detector CT assessment. Egypt J Radiol Nucl Med 2017;48(04):897-903

3 Peynegre R, Rouvier P. Anatomy and Anatomical Variations of the Paranasal Sinuses. In: Gershwin ME, Incaudo GA, editors. Diseases of the Sinuses [Internet]. Totowa, NJ: Humana Press; 1996:3-32. Available from: http://link.springer.com/10.1007/978-1-4612-0225-7_1

4 Duque CS, Casiano RR. Surgical Anatomy and Embryology of the Frontal Sinus. In: Kountakis SE, Senior BA, DrafW, editors. The Frontal Sinus [Internet]. Berlin/Heidelberg: Springer-Verlag; 2005:21-31. Available from: http://link.springer.com/10.1007/3-540-27607-6_3

5 Loury MC. Endoscopic frontal recess and frontal sinus ostium dissection. Laryngoscope 1993;103(4 Pt 1):455-458

6 Karanfilov BI, Kuhn FA. The Endoscopic Frontal Recess Approach. In: Kountakis SE, Senior BA, Draf W, editors. The Frontal Sinus [Internet]. Berlin/Heidelberg: Springer-Verlag; 2005:179-89. Available from: http://link.springer.com/10.1007/3-540-27607-6_20

7 Friedman M, Bliznikas D, Vidyasagar R, Landsberg R. Frontal sinus surgery 2004: update of clinical anatomy and surgical techniques1 1The authors received no financial support in connection with this article, and deny any off-label or investigational usage of any product. Oper Tech Otolaryngol-Head Neck Surg 2004;15 (01):23-31

8 Ximendes R, Mangussi-Gomes J, Balieiro FO, et al. Anatomical relations between the frontal sinus drainage pathway and the agger nasi cell. J Otolaryngol ENT Res 2018

9 Gaafar H, Abdel-Monem MH, Qawas MK. Frontal sinus outflow tract "anatomic study". Acta Otolaryngol 2001;121(02):305-309

10 Stamm A, Nogueira JF, Americo RR, Solferini Silva ML. Frontal sinus approach: the 'vertical bar' concept. Clin Otolaryngol 2009; 34(04):407-408

11 Daniels DL, Mafee MF, Smith MM, et al. The frontal sinus drainage pathway and related structures. AJNR Am J Neuroradiol 2003;24 (08):1618-1627

12 H S. W P. Functional Endoscopic Sinus Surgery. Concept, Indications and Results of the Messerklinger Technique [Internet]. European archives of oto-rhino-laryngology: official journal of the European Federation of Oto-Rhino-Laryngological Societies (EUFOS): affiliated with the German Society for Oto-Rhino-Laryngology - Head and Neck Surgery. 1990 [cited 2020 Mar 13]. Available from: https://pubmed.ncbi.nlm.nih.gov/2180446/? from_term=stammberger + frontal + sinus\&from_pos $=9$

13 Fatu C, Puisoru M, Rotaru M, Truta AM. Morphometric evaluation of the frontal sinus in relation to age. Ann Anat 2006;188(03): 275-280

14 Lee D, Brody R, Har-El G. Frontal sinus outflow anatomy. Am J Rhinol 1997;11(04):283-285

15 Bent JP, Cuilty-Siller C, Kuhn FA. The Frontal Cell As a Cause of Frontal Sinus Obstruction. Am J Rhinol 1994;8(04):185-191

16 Wormald P-J, Hoseman W, Callejas C, et al. The International Frontal Sinus Anatomy Classification (IFAC) and Classification of the Extent of Endoscopic Frontal Sinus Surgery (EFSS). Int Forum Allergy Rhinol 2016;6(07):677-696

17 Weber RK, Hosemann W. Comprehensive review on endonasal endoscopic sinus surgery. GMS Curr Top Otorhinolaryngol Head Neck Surg 2015;14:Doc08 
18 Kasbekar AV, Swords C, Attlmayr B, Kulkarni T, Swift AC. Sinonasal papilloma: what influences the decision to request a magnetic resonance imaging scan? J Laryngol Otol 2018;132(07):584-590

19 Reitzen SD, Wang EY, Butros SR, Babb J, Lebowitz RA, Jacobs JB. Three-dimensional reconstruction based on computed tomography images of the frontal sinus drainage pathway. J Laryngol Otol 2010;124(03):291-296

20 Wormald PJ. The agger nasi cell: the key to understanding the anatomy of the frontal recess. Otolaryngol Head Neck Surg 2003; 129(05):497-507

21 Kennedy DW, Senior BA. Endoscopic sinus surgery. A review. Otolaryngol Clin North Am 1997;30(03):313-330

22 Teshima M, Shinomiya H, Otsuki N, et al. Complications in Salvage Surgery for Nasal and Paranasal Malignant Tumors Involving the Skull Base. J Neurol Surg B Skull Base 2018;79(03):224-228

23 Snidvongs K, Pratt E, Chin D, Sacks R, Earls P, Harvey RJ. Corticosteroid nasal irrigations after endoscopic sinus surgery in the management of chronic rhinosinusitis. Int Forum Allergy Rhinol 2012;2(05):415-421

24 Kuhn FA, Melroy CT, Dubin MG, Ventrapragada S. Frontal Sinus Instrumentation. In: Kountakis SE, Önerci M, editors. Rhinologic and Sleep Apnea Surgical Techniques [Internet]. Berlin, Heidelberg: Springer Berlin Heidelberg; 2007:27-39. Available from: http://link.springer.com/10.1007/978-3-540-34020-1_3

25 Bruggers S, Sindwani R. Evolving trends in powered endoscopic sinus surgery. Otolaryngol Clin North Am 2009;42(05):789-798, viii

26 Graham SM, Nerad JA. Orbital complications in endoscopic sinus surgery using powered instrumentation. Laryngoscope 2003;113 (05):874-878

27 Dalgorf DM, Sacks R, Wormald P-J, et al. Image-guided surgery influences perioperative morbidity from endoscopic sinus surgery: a systematic review and meta-analysis. Otolaryngol Head Neck Surg 2013;149(01):17-29

28 Metson R. Image-guided sinus surgery: lessons learned from the first 1000 cases. Otolaryngol Head Neck Surg 2003;128(01):8-13

29 Kolia NR, Man L-X. Total intravenous anaesthesia versus inhaled anaesthesia for endoscopic sinus surgery: a meta-analysis of randomized controlled trials. Rhinology 2019;57(06):402-410

30 Wormald PJ, van Renen G, Perks J, Jones JA, Langton-Hewer CD. The effect of the total intravenous anesthesia compared with inhalational anesthesia on the surgical field during endoscopic sinus surgery. Am J Rhinol 2005;19(05):514-520

31 Hathorn IF, Habib A-RR, Manji J, Javer AR. Comparing the reverse Trendelenburg and horizontal position for endoscopic sinus surgery: a randomized controlled trial. Otolaryngol Head Neck Surg 2013;148(02):308-313

32 Ping W-D, Zhao Q-M, Sun H-F, Lu H-S, Li F. Role of tranexamic acid in nasal surgery: A systemic review and meta-analysis of randomized control trial. Medicine (Baltimore) 2019;98(16): e15202

33 Ottoline ACX, Tomita S, Marques Mda PC, Felix F, Ferraiolo PN, Laurindo RSS. Antibiotic prophylaxis in otolaryngologic surgery. Int Arch Otorhinolaryngol 2013;17(01):85-91
34 Shah J, Roxbury CR, Sindwani R. Techniques in Septoplasty: Traditional Versus Endoscopic Approaches. Otolaryngol Clin North Am 2018;51(05):909-917

35 Draf W. Endonasal Frontal Sinus Drainage Type I-III According to Draf. In: Kountakis SE, Senior BA, Draf W, editors. The Frontal Sinus [Internet]. Berlin/Heidelberg: Springer-Verlag; 2005:219-32. Available from: http://link.springer.com/10.1007/3-540-27607-6_24

36 DeConde AS, Smith TL. Outcomes After Frontal Sinus Surgery: An Evidence-Based Review. Otolaryngol Clin North Am 2016;49(04): 1019-1033

37 Stamm AC, Draf W, Eds. Micro-endoscopic Surgery of the Paranasal Sinuses and the Skull Base [Internet]. Berlin, Heidelberg: Springer Berlin Heidelberg; 2000. Available from: http://link. springer.com/10.1007/978-3-642-57153-4

38 Rudert H. [Microscope and endoscope-assisted surgery of inflammatory diseases of the paranasal sinuses. Value of the Messerklinger infundibulotomy]. HNO 1988;36(12):475-482

39 Carney AS. Draf III frontal sinus surgery: "How I do it". Am J Rhinol Allergy 2017;31(05):338-340

40 Sahu N, Casiano RR. Nasal branch of the anterior ethmoid artery: a consistent landmark for a midline approach to the frontal sinus. Int Forum Allergy Rhinol 2019;9(05):562-566

41 Conger BT Jr, Riley K, Woodworth BA. The Draf III mucosal grafting technique: a prospective study. Otolaryngol Head Neck Surg 2012;146(04):664-668

42 Anderson P, Sindwani R. Safety and efficacy of the endoscopic modified Lothrop procedure: a systematic review and metaanalysis. Laryngoscope 2009;119(09):1828-1833

43 Naidoo Y, Bassiouni A, Keen M, Wormald PJ. Long-term outcomes for the endoscopic modified Lothrop/Draf III procedure: a 10-year review. Laryngoscope 2014;124(01):43-49

44 Naidoo Y, Bassiouni A, Keen M, Wormald P-J. Risk factors and outcomes for primary, revision, and modified Lothrop (Draf III) frontal sinus surgery. Int Forum Allergy Rhinol 2013;3(05):412-417

45 Graham SM. Complications of Frontal Sinus Surgery. In: Kountakis SE, Senior BA, Draf W, editors. The Frontal Sinus [Internet]. Berlin/Heidelberg: Springer-Verlag; 2005:267-73. Available from: http://link.springer.com/10.1007/3-540-27607-6_29

46 Psaltis AJ, Schlosser RJ, Banks CA, Yawn J, Soler ZM. A systematic review of the endoscopic repair of cerebrospinal fluid leaks. Otolaryngol Head Neck Surg 2012;147(02):196-203

47 Schlosser RJ, Bolger WE. Nasal cerebrospinal fluid leaks: critical review and surgical considerations. Laryngoscope 2004;114(02): 255-265

48 Welch KC, Palmer JN. Intraoperative emergencies during endoscopic sinus surgery: CSF leak and orbital hematoma. Otolaryngol Clin North Am 2008;41(03):581-596, ix-x

49 Han JK, Higgins TS. Management of orbital complications in endoscopic sinus surgery. Curr Opin Otolaryngol Head Neck Surg 2010;18(01):32-36

50 Goldstein GH, Kennedy DW. Long-term successes of various sinus surgeries: a comprehensive analysis. Curr Allergy Asthma Rep 2013;13(02):244-249 